\title{
Cerebrovascular Diseases
}

\section{Cerebrovasc Dis 2014;38:391-392 \\ DOI: $10.1159 / 000369002$ \\ Practical Applications of Predictive Models for Malignant Middle Cerebral Artery Infarction}

Dale Ding

University of Virginia, Department of Neurological Surgery, (Institute where work was conducted), Charlottesville, Va., USA

I have read, with interest, a recent article in Cerebrovascular Diseases by MacCallum et al. titled 'Low Alberta Stroke Program Early CT Score (ASPECTS) Associated with Malignant Middle Cerebral Artery Infarction' [1]. The authors analyzed the radiographic imaging of 108 patients with malignant middle cerebral artery (MCA) infarction (MMI) and found that an ASPECTS of 7 or lower was predictive of MMI. Specifically, the incidences MMI with an ASPECTS of 7 or lower compared to greater than 7 were 77 and $35 \%$, respectively ( $\mathrm{p}<0.001)$, whereas the incidences of non-malignant MCA infarction with an ASPECTS of 7 or lower compared to greater than 7 were 23 and $65 \%$, respectively ( $p<0.001$ ). The diagnostic cut-off value of 7 provided a $50 \%$ sensitivity and $86 \%$ specificity for MMI. This timely and insightful study uses a straightforward and validated scale (i.e., ASPECTS) to quickly and reliably predict the subsequent development of MMI. Thus, the diagnostic approach proposed by the authors has the potential to guide medical management and surgical intervention for patients with large territory MCA infarctions. However, a number of other predictive models for MMI have been previously described. In the following, our goal is to discuss the potential practical applications of these predictive models in the clinical setting.

MMI is a clinically devastating disease process, which is associated with high rates of neurological morbidity, mortality, and poor functional outcome despite aggressive medical and surgical management [2]. While the survival benefit of decompressive craniectomy for patients with MMI has been established by multiple randomized controlled trials, its benefit for functional outcomes remains controversial and is potentially affected by the duration of follow-up, dichotomization of favorable versus unfavorable outcomes, and time frame within which a surgery is performed [3-5]. The three-year follow-up results of the Hemicraniectomy After Middle cerebral artery infarction with Life-threatening Edema. Trial (HAMLET) showed, incongruence with the one year results from the same study that decompressive craniectomy decreased mortality but did not affect functional outcomes secondary to MMI [6]. A recent survey of nearly 2,000 stroke physicians showed a lack of consensus regarding the management of MMI and acceptable outcome following MMI [7].

Shimoyama et al. developed a predictive model of MMI by retrospectively analyzing 119 patients with large territory middle ce- rebral artery (MCA) infarction [8]. Approximately, half of the patients included in the study (48\%) developed MMI. There were no differences between the MMI and non-MMI cohorts in baseline patient demographics, medical comorbidities, or neurological exam at presentation as measured by the National Institute of Health Stroke Scale (NIHSS). Taking into account the computed tomography $(\mathrm{CT})$ and magnetic resonance imaging (MRI) radiologic findings and serum laboratory data, the authors performed multivariate logistic regression analysis to identify anterior cerebral artery territory involvement $(\mathrm{p}=0.002)$, serum glucose of at least $145 \mathrm{mg} / \mathrm{dl}(\mathrm{p}=0.002)$, MCA M1 segment susceptibility vessel sign $(\mathrm{p}=0.013)$, and diffusion-weighted imaging (DWI) ASPECTS $(\mathrm{p}=0.012)$ as independent predictors of MMI. In the derived DASH score, each of the aforementioned predictors of MMI was assigned one point for a total score, which ranged from zero to four. The authors then show that the DASH score correlated to the likelihood of developing MMI.

Kruetzelmann et al. found that the addition of 24-hour NIHSS of at least 22 to DWI lesion volume of at least $78 \mathrm{ml}$ increased the sensitivity of the predictive model from 59 to $79 \%$ based on DWI alone without significantly affecting specificity, positive predictive value, or negative predictive value [9]. The use of clinical assessment contrasts this predictive model from the one in the current study, which utilizes only radiographic findings. However, both models utilize neuroimaging features and an aim to distinguish patients presenting with large territory MCA infarcts into those who will versus those who will not develop malignant cerebral edema. Ultimately, this distinction is crucial to optimizing the management of MMI patients, especially with regard to surgical decision making. The ideal predictive model is not only able to accurately identify its target outcome but also able to be easily and practically employed in clinical practice. Therefore, a balance must exist between including too many and too few variables in models designed to predict specific radiologic or clinical outcomes. Whether the use of an ASPECTS cut-off of 7 represents an improvement over its predecessors for predicting MMI remains to be determined pending external validation with larger, more diverse patient populations.

\section{References}

1 MacCallum C, Churilov L, Mitchell P, Dowling R, Yan B: Low Alberta Stroke Program Early CT Score (ASPECTS) associated with malignant middle cerebral artery infarction. Cerebrovasc Dis 2014;38:39-45.

-2 Hacke W, Schwab S, Horn M, Spranger M, De Georgia M, von Kummer R: 'Malignant' middle cerebral artery territory infarction: clinical course and prognostic signs. Arch Neurol 1996;53:309-315.

-3 Vahedi K, Hofmeijer J, Juettler E, Vicaut E, George B, Algra A, Amelink GJ, Schmiedeck P, Schwab S, Rothwell PM, Bousser MG, van der Worp $\mathrm{HB}$, Hacke W: Early decompressive surgery in malignant infarction of the middle cerebral artery: a pooled analysis of three randomised controlled trials. Lancet Neurol 2007;6:215-222.

\section{KARGER}

E-Mail karger@karger.com

www.karger.com/ced
(C) 2014 S. Karger AG, Basel

$1015-9770 / 14 / 0385-0391 \$ 39.50 / 0$
Dale Ding, MD

University of Virginia, Department of Neurological Surgery

P.O. Box 800212

Charlottesville, VA 22908 (USA)

E-Maildmd7q@hscmail.mcc.virginia.edu 
4 Hofmeijer J, Kappelle LJ, Algra A, Amelink GJ, van Gijn J, van der Worp HB: Surgical decompression for space-occupying cerebral infarction (the Hemicraniectomy After Middle Cerebral Artery Infarction with Lifethreatening Edema Trial [HAMLET]): a multicentre, open, randomised trial. Lancet Neurol 2009;8:326-333.

5 Juttler E, Schwab S, Schmiedek P, Unterberg A, Hennerici M, Woitzik J, Witte S, Jenetzky E, Hacke W: Decompressive Surgery for the Treatment of Malignant Infarction of the Middle Cerebral Artery (DESTINY): a randomized, controlled trial. Stroke 2007;38:2518-2525.

6 Geurts M, van der Worp HB, Kappelle LJ, Amelink GJ, Algra A, Hofmeijer J: Surgical decompression for space-occupying cerebral infarction: outcomes at 3 years in the randomized HAMLET trial. Stroke 2013;44: 2506-2508.
7 Neugebauer H, Creutzfeldt CJ, Hemphill JC 3rd, Heuschmann PU, Juttler E: DESTINY-S: attitudes of physicians toward disability and treatment in malignant MCA infarction. Neurocrit Care 2014;21:27-34.

8 Shimoyama T, Kimura K, Uemura J, Yamashita S, Saji N, Shibazaki K, Iguchi Y: The DASH score: a simple score to assess risk for development of malignant middle cerebral artery infarction. J Neurol Sci 2014;338: 102-106.

9 Kruetzelmann A, Hartmann F, Beck C, Juettler E, Singer OC, Kohrmann M, Kersten JF, Sobesky J, Gerloff C, Villringer A, Fiehler J, NeumannHaefelin T, Schellinger PD, Rother J, Thomalla G: Combining magnetic resonance imaging within six-hours of symptom onset with clinical follow-up at $24 \mathrm{~h}$ improves prediction of 'malignant' middle cerebral artery infarction. Int J Stroke 2014;9:210-214. 